\title{
Progressive back pain due to epidural hygroma: an infrequent complication of lumbar puncture in adults
}

\author{
María Rico-Santos, ${ }^{1}$ Javier Villafani, ${ }^{2}$ Antonio Sáiz, ${ }^{3}$ Pedro Oliva Nacarino ${ }^{2}$
}

${ }^{1}$ Department of Neurology, Hospital de Cabueñes, Gijón Asturias, Spain

${ }^{2}$ Department of Neurology, Hospital Universitario Central de Asturias, Oviedo,

Asturias, Spain

${ }^{3}$ Department of Radiology, Hospital Universitario Central de Asturias, Oviedo,

Asturias, Spain

\section{Correspondence to} Dr María Rico-Santos, mricos@gmail.com

Accepted 28 July 2015
CrossMark

To cite: Rico-Santos $M$, Villafani J, Sáiz A, et al. BMJ Case Rep Published online: [please include Day Month Year] doi:10.1136/bcr-2015211379

\section{DESCRIPTION}

A 25-year-old woman was admitted to the emergency department with orthostatic headache, nausea and dorsal stabbing pain not relieved with decubitus. Two days prior, she had undergone lumbar puncture after consulting for malaise, fever and headache. After admission, the pain progressed to the cervical and lumbar areas, though neurological examinations were normal. A spinal MRI showed an epidural cerebrospinal fluid (CSF) collection, which extended from D1 to S1 vertebral levels, displacing the spinal cord forward and surrounding the thecal sac (figure 1). During the following $48 \mathrm{~h}$, the pain worsened, such that lying prone was the only position the patient tolerated. Analgaesia with NSAIDs, opioids, corticoids and caffeine failed to provide relief, so 5 days after admission an epidural blood patch (EBP) was

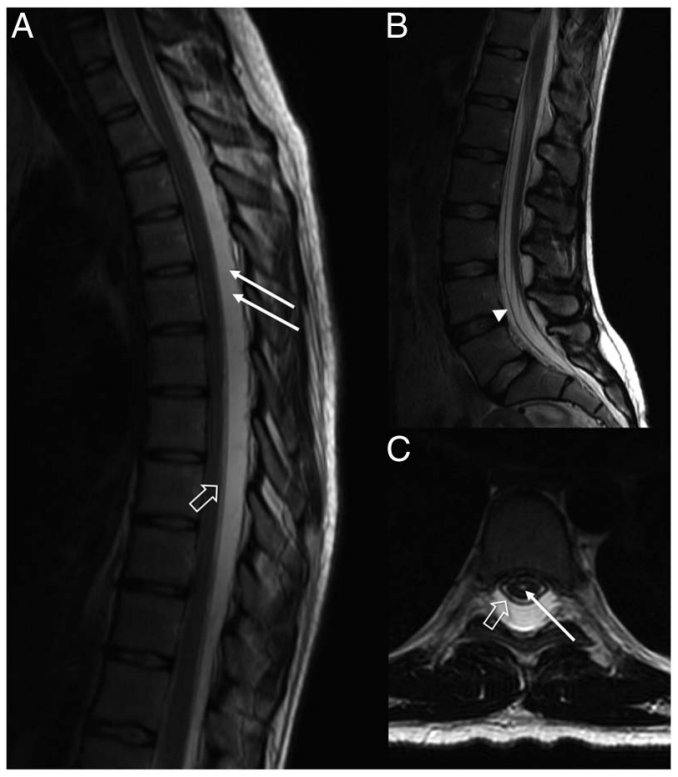

Figure 1 Diagnostic spinal cord T2-weighted MRI. Sagittal view showing the epidural cerebrospinal fluid (CSF) collection (white arrows), extending from T1 to S1, displacing the dura mater (open arrow) and the spinal cord forward. Note the absence of CSF flow artefacts (A). At the lower levels, the collection can be seen surrounding the dural sac as a result of the detachment of the dura (arrow head) (B). In the axial view, the dura mater around the spinal cord at the dorsal level can be seen (open arrow), as a result of the compression caused by the hygroma. A dilation of the central canal is present (white arrow) (C).

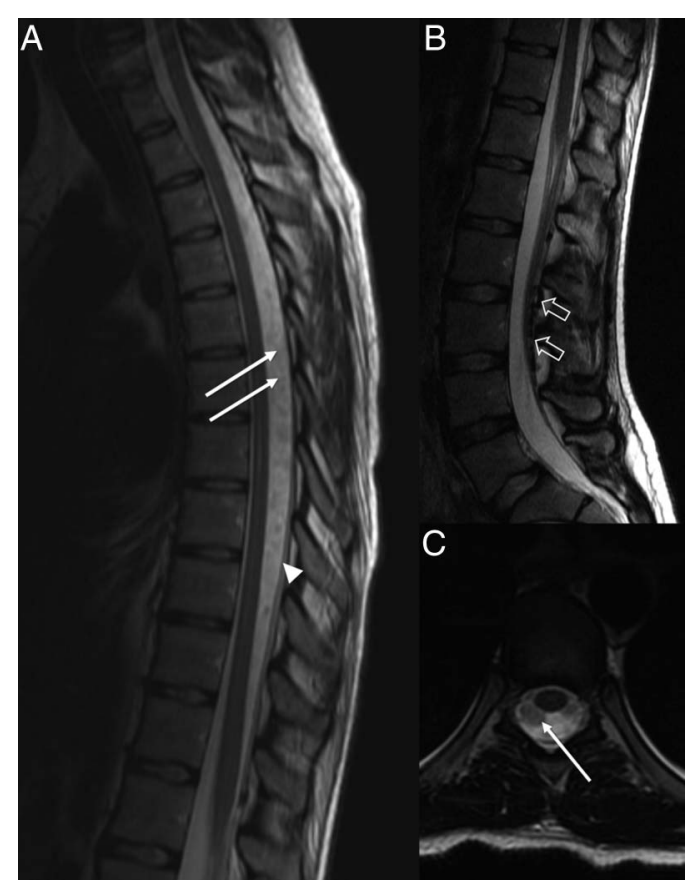

Figure 2 Post-epidural blood patch (EBP) implant spinal cord T2-weighted MRI. Sagittal views showing the dura mater back at its normal position (arrow head) and reabsorption of the cerebrospinal fluid (CSF) collection, with normal CSF flow artefacts in the subarachnoid space (white arrows) (A). A diffuse smooth thickening of the dura can be seen in the lumbosacral cuts, representing the blood patch in the epidural space (open arrows) (B). Axial detail at the same level as figure 1 shows the disappearance of the hypointense dura surrounding the spinal cord and CSF flow artefacts (white arrow) (C).

decided on. Twenty cubic centimetres of autologous blood were injected into the epidural space within the L4-L5 level. After the procedure, the back pain subsided immediately, allowing the patient to maintain a sitting position for brief periods of time. She was left with only a mild orthostatic headache; this progressively disappeared over the next few days. A second MRI carried out $24 \mathrm{~h}$ later demonstrated complete reabsorption of the CSF collection, with the spinal cord and dura mater back at their normal positions. Also, the blood patch could be seen spreading through the lower levels (figure 2). After being in observation for possible complications of the EBP and successful withdrawal of pain medication, the patient was discharged 5 days after the procedure, pain free. She has remained asymptomatic ever since. 


\section{Learning points}

- Epidural cerebrospinal fluid (CSF) hygromas are mostly seen in children and neonates, but can also occur in adults, where they might be underdiagnosed. When these collections become clinically expressive, they usually present with severe pain, and only rarely with neurological signs on physical examination. ${ }^{12}$

- Although traumatic lumbar puncture has been recognised as a risk factor for developing a dural tear, evidence to date does not clearly establish a correlation between this and an epidural CSF collection, and data identifying patients at risk are scarce, so physicians should be aware of the warning signs. Severe and progressing back pain extending beyond the puncture point and not related to position, or new neurological symptoms after lumbar puncture, should prompt spinal MRI. $^{3}$

- As these collections spontaneously regress in a few days in most cases, conservative management is usually recommended. Nevertheless, in patients suffering from severe and persistent pain, an epidural blood patch implant is a valuable resource because of its rapid effectiveness. Symptoms after the procedure may include back and radicular pain, but otherwise it is a relatively safe procedure. $^{3}$
Acknowledgements The authors would like to thank Dr Natalia Perez de Arriba for collaborating in the implant of the blood patch.

Contributors MR-S, JV and PON evaluated the patient in inpatient clinic. JV followed the patient in outpatient clinic. AS performed the radiological examination. MR-S collected the data and wrote the manuscript. All the authors were involved in the conception of the work and revised it critically for important intellectual content. All the authors approved the final version to be submitted and published.

Competing interests None declared.

Patient consent Obtained.

Provenance and peer review Not commissioned; externally peer reviewed.

\section{REFERENCES}

$1 \mathrm{Ng} \mathrm{WH}$, Drake JM. Symptomatic spinal epidural CSF collection after lumbar puncture in a young adult: case report and review of literature. Childs Nerv Syst 2010;26:259-62.

2 Kiechl-Kohlendorfer U, Unsinn KM, Schlenck B, et al. Cerebrospinal fluid leakage after lumbar puncture: incidence and sonographic appearance. Am J Roentgenol 2003;181:231-4.

3 Paldino M, Mogilner AY, Tenner MS. Intracranial hypotension syndrome: a comprehensive review. Neurosurg Focus 2003;15:ECP2.

Copyright 2015 BMJ Publishing Group. All rights reserved. For permission to reuse any of this content visit http://group.bmj.com/group/rights-licensing/permissions.

BMJ Case Report Fellows may re-use this article for personal use and teaching without any further permission.

Become a Fellow of BMJ Case Reports today and you can:

- Submit as many cases as you like

- Enjoy fast sympathetic peer review and rapid publication of accepted articles

- Access all the published articles

- Re-use any of the published material for personal use and teaching without further permission

For information on Institutional Fellowships contact consortiasales@bmjgroup.com

Visit casereports.bmj.com for more articles like this and to become a Fellow 